\title{
Targeting histone deacetylase activity to arrest cell growth, reduce pluripotency, and promote differentiation in Ewing sarcoma
}

\author{
Bárbara Kunzler Souza ${ }^{1,2}$, Patrícia Luciana da Costa Lopez ${ }^{3}$, Pâmela Rossi Menegotto ${ }^{1,2}$, \\ Igor Araujo Vieira ${ }^{4}$, Nathalia Kersting ${ }^{1}$, Ana Lúcia Abujamra ${ }^{1,5}$, André T. Brunette ${ }^{1,5}$, \\ Algemir L. Brunette ${ }^{1,5}$, Lauro Gregianin ${ }^{1,6,7}$, Caroline Brunetto de Farias ${ }^{1,5}$, Carol J. \\ Thiele $^{8}$, and Rafael Roesler ${ }^{1,2, *}$ \\ ${ }^{1}$ Cancer and Neurobiology Laboratory, Experimental Research Center, Clinical Hospital (CPE- \\ HCPA), Federal University of Rio Grande do Sul, 90035-003 Porto Alegre, RS, Brazil. \\ ${ }^{2}$ Department of Pharmacology, Institute for Basic Health Sciences, Federal U niversity of Rio \\ Grande do Sul, 90050-170 Porto Alegre,RS, Brazil. \\ ${ }^{3}$ Graduate Program in Gastroenterology and Hepatology, School of Medicine, Federal University \\ of Rio Grande do Sul, 90035-003 Porto Alegre, RS, Brazil. \\ ${ }^{4}$ Laboratory of Genomic Medicine, Experimental Research Center, Clinical Hospital (CPE-HCPA), \\ Federal University of Rio Grande do Sul, 90035-003 Porto Alegre, RS, Brazil. \\ ${ }^{5}$ Rafael Koff Acordi Research Center, Children's Cancer Institute, 90620-110 Porto Alegre, RS, \\ Brazil. \\ ${ }^{6}$ Department of Pediatrics, School of Medicine, Federal University of Rio Grande do Sul, \\ 90035-003 Porto Alegre, RS, Brazil. \\ ${ }^{7}$ Pediatric Oncology Service, Clinical Hospital, Federal University of Rio Grande do Sul, \\ 90035-003 Porto Alegre, RS, Brazil. \\ ${ }^{8}$ Cell \& Molecular Biology Section, Pediatric Oncology Branch, National Cancer Institute, National \\ Institutes of Health, Bethesda, 20892, MD, USA.
}

\section{Abstract \\ There is an urgent need for advances in the treatment of Ewing sarcoma (EWS), an aggressive childhood tumor with possible neuroectodermal or mesenchymal origin. Inhibition of histone deacetylases (HDAC) can revert aberrant epigenetic states and reduce growth in different}

\footnotetext{
*Correspondence: Rafael Roesler. Department of Pharmacology, Institute for Basic Health Sciences, Federal University of Rio Grande do Sul, Rua Sarmento Leite, 500 (ICBS, Campus Centro/UFRGS), 90050-170 Porto Alegre,RS, Brazil. Telephone: +5551 33083183; fax: +5551 33083121.rafaelroesler@hcpa.edu.br.

Author Contributions

B.K.S., P.L.C.L. and R.R designed experiments. B.K.S. and R.R. drafted the manuscript. B.K.S. performed all experiments, analysis and interpretation of data, and figure generation. P.L.C.L provided technical assistance for flow cytometry, immunofluorescence experiments and interpretation of data. P.R.M. provided technical assistance for cell culture drug treatments and tumorsphere induction experiments. I.A.V. and N.K. provided technical assistance for cell culture experiments, protein extraction and western blotting.

A.L.A., A.T.A, A.L.B., L.G., C.B.F. and R.R. acquired materials. C.B.F. and R.R. supervised the project. A.L.A., A.T.A, A.L.B., L.G., C.B.F., C.J.T. and R.R. critically edited the manuscript. All authors reviewed the manuscript.

Competing financial interests: The authors declare no competing financial interests.
} 
experimental cancer types. Here, we investigated whether the potent HDAC inhibitor, sodium butyrate $(\mathrm{NaB})$ has the ability to reprogram EWS cells towards a more differentiated state and affect their growth and survival. Exposure of two EWS cell lines to $\mathrm{NaB}$ resulted in rapid and potent inhibition of HDAC activity $\left(1 \mathrm{~h}, \mathrm{IC}_{50} 1.5 \mathrm{mM}\right)$ and a significant arrest of cell cycle progression $\left(72 \mathrm{~h}, \mathrm{IC}_{50} 0.68-0.76 \mathrm{mM}\right.$ ), marked by G0/G1 accumulation. Delayed cell proliferation and reduced colony formation ability were observed in EWS cells after long-term culture. NaB-mediated effects involved suppression of cell proliferation accompanied by decreased expression of key survival and pluripotency-associated genes, and the re-expression of the differentiation neuronal marker $\beta$ III-tubulin. Finally, we observed a marked activity of $\mathrm{NaB}$ in impairing survival of putative EWS cancer stem cells. Our findings support the use of HDAC inhibition as a therapeutic approach to impair cell growth and survival and to reprogram EWS tumors towards differentiation.

\section{Introduction}

Ewing sarcoma (EWS), a highly aggressive bone and soft tissue cancer, is the second most common primary solid bone malignancy in children and young adults ${ }^{1}$. Despite advances in multimodal therapy, patients with the disease have a poor prognosis, with a survival rate of $50-65 \%$ at 5 years and less than $30 \%$ for metastatic or refractory tumors ${ }^{2}$. EWS tumors typically harbor a specific genetic alteration characterized by a chromosomal translocation resulting in fusions between the EWS RNA Binding Protein 1 (EWSR1) gene and one of the several ETS family genes (most frequently $F L I-1$ ) which is frequent in $85 \%$ of cases ${ }^{1,3}$. EWS tumors are poorly differentiated and its cell of origin remains elusive and highly debated. Evidence indicates that EWS may arise from either developing neural crest cells ${ }^{4-7}$ or mesenchymal stem cells ${ }^{8-11}$.

Overall, EWS tumors are relatively genetically stable, since they harbor few somatic mutations compared with most other cancer types ${ }^{12}$. However, many epigenetic alterations are likely crucial for EWS tumorigenesis. EWSR1-FLI-1 acts as an aberrant transcription factor that induces chromatin remodeling to repress tumor suppressors while activating oncogenes ${ }^{13}$. The chromatin state in EWS is strikingly similar to that found in bonemarrow-derived mesenchymal stem cells. The increased chromatin accessibility in stem cells may lead to a state that facilitates oncogenic alterations induced by EWSR1-FLI-1, suggesting a stem cell origin for EWS ${ }^{14}$. Epigenetic alterations in EWS include DNA methylation or post-translational modifications to histones, including acetylation, which are key in regulating gene expression ${ }^{15,16}$.

Epigenetic changes provide potentially druggable targets ${ }^{17}$. A balance between the opposing activities of histone acetyltransferases (HATs) and deacetylases (HDACs) is key in regulating gene expression. Histone acetyltransferases (HATs) control histone acetylation activity through the transfer of acetyl groups to the amino-terminal lysine residues of histones, thus increasing transcriptional activity. In contrast, histone deacetylases (HDACs) remove acetyl groups, favoring chromatin condensation and repression of gene expression ${ }^{18}$. HDAC inhibitors (HDi), represent a class of experimental antineoplastic agents to target aberrant epigenetic alterations found in cancer. The anti-tumor effects caused by HDi 
commonly involve alterations in cell cycle, differentiation and apoptosis. Several HDis are being developed and extensively evaluated in vitro and in vivo ${ }^{19}$. However, to date only three HDAC inhibitors have been approved by the Food and Drug Administration, namely vorinostat (SAHA), romidepsin (Istodax) and belinostat (Beleodaq) for treatment of peripheral T-cell and cutaneous T-cell lymphomas ${ }^{20}$. Sodium butyrate $(\mathrm{NaB})$ is a short fatty acid that acts as a potent class I and IIa HDAC inhibitor inducing arrest in proliferation of cancer cells by increasing histone acetylation. In mammalian cells, $\mathrm{NaB}$ promotes hyperacetylation of the histones $\mathrm{H} 3$ and $\mathrm{H} 4$, resulting in chromatin decondensation and increased transcriptional activity ${ }^{21}$. In EWS cells, we have previously shown a synergistic antitumor effect of $\mathrm{NaB}$ combined with commonly chemotherapeutic drugs ${ }^{22}$. Moreover, SAHA showed a synergistically enhanced antitumor activity upon combination with etoposide ${ }^{23}$, and $\mathrm{NaB}$, SAHA or entinostat or MS-275 as monotherapies or combined with TRAIL display an additive cytotoxic effect in EWS cells ${ }^{24}$.

Here, we show that inhibition of global HDAC activity by $\mathrm{NaB}$ suppresses multiple pathways involved in cell proliferation, survival and pluripotency. In addition, $\mathrm{NaB}$ exposure stimulates morphologic and biochemical aspects of neural differentiation in EWS cells.

\section{Results}

\section{Inhibition of HDAC activity induces growth arrest in EWS cells}

To examine the effect of $\mathrm{NaB}$ on HDAC activity in EWS cells, we exposed SK-ES1 and RDES cells to $\mathrm{NaB}$ for 1 and $3 \mathrm{~h}$. HDAC activity was significantly reduced after $1 \mathrm{~h}$ when $\mathrm{NaB}$ doses higher than $1 \mathrm{mM}$ were used, resulting in a target $\mathrm{IC}^{50}$ of approximately $1.5 \mathrm{mM}$ (Fig. $1 \mathrm{~A}, \mathrm{C}$ ). HDAC activity in cells exposed to $\mathrm{NaB}$ for $3 \mathrm{~h}$ was not as effectively reduced in comparison to $1 \mathrm{~h}$ treatments, and a significant decrease was observed only in RD-ES cells exposed to $2 \mathrm{mM}$ of $\mathrm{NaB}$ (see Supplementary Fig. S1 online), suggesting that $\mathrm{NaB}$ optimally inhibits HDAC activity in EWS cells at a kinetic rate of $1 \mathrm{~h}$.

In order to evaluate the biological effect of HDAC activity inhibition, we exposed EWS cells to varying concentrations of $\mathrm{NaB}(0.5-5 \mathrm{mM})$ for $72 \mathrm{~h}$. HDAC activity inhibition potently affected cell viability of both cell lines (Fig. 1B). At $72 \mathrm{~h}$, the biological $\mathrm{IC}_{50}$ of $\mathrm{NaB}$ was 0.76 and $0.68 \mathrm{mM}$ for SK-ES 1 and RD-ES EWS cell lines, respectively (Fig. 1C). Interestingly, cells exposed to $\mathrm{NaB}$ showed a change in morphology accompanied by the appearance of short neurite-like extensions (Fig. 1D).

Next, we verified whether inhibition of HDAC activity by $\mathrm{NaB}$ would change cell cycle distribution. HDAC inhibition resulted in a significant alteration in EWS cell cycle featuring an accumulation of cells in the G0/G1 phase $35 \mathrm{~h}$ after $\mathrm{NaB}$ exposure. In the SK-ES1 EWS cell line, we also observed a significant decrease in the $\mathrm{S}$ and G2/M phases of the cell cycle while in the RD-ES cell line there was a significant reduction in polyploidy (Fig. 2A). To determine whether HDAC activity inhibition disrupts histone 3 phos-S10 (chromosome condensation marker during mitosis ${ }^{25}$ ), we immunostained EWS cell lines exposed to $\mathrm{NaB}$ for $72 \mathrm{~h}$ against anti-H3 phos-S10 plus anti-Alexa488, measured by laser confocal microscopy. As expected, H3 phos-S10 immunolocalized to the nucleus in both EWS cell lines (Fig. 2B). In addition, we observed that both EWS cell lines exposed to higher doses of 
$\mathrm{NaB}$ ( 2 and $5 \mathrm{mM}$ ) showed a reduced $\mathrm{H} 3$ phos-S10 level, whereas there was no significant change at lower doses $(0.5$ and $1 \mathrm{mM})$ compared to untreated cells (Fig. 2C). Given that Cyclin D1 is a G1-phase regulator protein overexpressed in EWS, we investigated whether the HDAC activity function regulate Cyclin D1 expression after $72 \mathrm{~h}$ of NaB exposure. SKES 1 cells exposed to 0.5 or $1 \mathrm{mM}$ of $\mathrm{NaB}$ showed an approximately 1.5 -fold change decrease in Cyclin D1 levels, and $1 \mathrm{mM} \mathrm{NaB}$ also decreased Cyclin D1 levels also in RD-ES cells (Fig. 2D). These results suggest that HDAC activity inhibition induces growth arrest, which inhibits EWS cell proliferation potential.

\section{HDAC inhibition abrogates cell proliferation and survival pathways in EWS cells}

To investigate molecular mechanisms associated with the NaB-induced decreases in EWS cell growth, we examined the expression of key proteins that control cell survival and proliferation. After exposure to either 0.5 or $1.0 \mathrm{mM} \mathrm{NaB}$, a decrease in the levels of survival-promoting neurotrophins, brain-derived neurotrophic factor (BDNF) and nerve growth factor (NGF) were observed (Fig. 3A). We also immunostained tropomyosin receptor kinase B (TrkB) in EWS cell lines against anti-TrkB, plus anti-Rhodamine. As expected, TrkB immunoreactivity was detected in the cytoplasm. In addition, we observed that TrkB levels were reduced in a dose-dependent manner in both cell lines after $\mathrm{NaB}$ exposure (Fig. 2B, C). Consistently with this finding, we also observed a decrease in protein levels of downstream targets phosphorylated extracellular-regulated kinase (pERK), but not total ERK1 levels, and pAKTS473 as well as total AKT. Essentially similar effects were observed in RD-ES cells, however only at the $1.0 \mathrm{mM}$ dose of $\mathrm{NaB}$ (Fig. 3D). The analysis of relative densitometric units related to the immunoblots is depicted in Fig. 3E. These results support the possibility that signaling mediated by neurotrophins, ERK and AKT are involved in mediating the inhibitory effects of $\mathrm{NaB}$ in EWS cells.

\section{Persistence of the anti-proliferative effect induced by HDAC inhibition in EWS cells}

We performed a cumulative population doubling (CPD) of EWS cells to examine the persistence of the anti-proliferative effect of $\mathrm{NaB}$. After $72 \mathrm{~h}$ of treatment, cells were maintained for 16 days in drug free media, as shown in Fig. 4A. Significant delays in cell proliferation rate were found with 2 and $5 \mathrm{mM}$ of $\mathrm{NaB}$ (Fig. 3B). Because the number of cells was too small, we modeled the growth from day 19 to 35 using a mathematical prediction described by Silva et al. ${ }^{26}$. We were able to predict whether EWS cells exposed to the higher doses of $\mathrm{NaB}$ over 35 days would have a persistent reduction in the ability to proliferate. Lower doses $(0.5$ and $1 \mathrm{mM})$ of $\mathrm{NaB}$ resulted in a gain in cell proliferation by day 20 which by 35 days was even higher than our prediction (Fig. 4B). It is possible that only a resistant subset of EWS cells could restore cell proliferative ability to an equal or higher degree compared to controls.

We then went on to perform a CPD profile analysis that examines long-term changes in cell population size. On the basis of CPD graphs from cell counting we calculated four different parameters: relative end CPD (RendCPD) to quantitatively assess the end point of cell proliferation analysis; relative area under curve (rAUC) to determine a global effect after treatment intervention; relative time to cross a threshold (RTCT) to measure the delay of the cell population that recovers growth after treatment; and relative proliferation rate (RPR) to 
quantify the relative regrowth velocity of the cells which survived after treatment intervention. The average of all parameters described above is termed the long-term survival index (LSI). HDAC activity inhibition in both cell lines, particularly after treatment with 5 $\mathrm{mM} \mathrm{NaB}$, resulted in a robust decrease in RPR and RTCT parameters (Fig. 4C), except the RPR parameter in which there was no significant change in SK-ES 1 cells (data not shown). These data show that the effects of $\mathrm{NaB}$ can persist in the long-term to delay the regrowth of the EWS cell population.

Finally, we performed a colony formation assay for 10 days in drug free media, after a 72-h exposure to $\mathrm{NaB}$. There was a significant reduction in the number of colonies in both cell lines after exposure to $\mathrm{NaB}$. Moreover, there was a significant decrease in the size of the colonies in SK-ES 1 cells after exposure to $5 \mathrm{mM} \mathrm{NaB}$ (Fig. 4D). These results indicate that the decrease in cell growth is also associated with the cells' colony forming capability.

\section{HDAC inhibition suppresses pluripotency-associated genes}

Previous studies have shown that the EWSR1/FLI-1 oncoprotein stimulates the pluripotency gene BMI-1, thus influencing EWS cell self-renewal ${ }^{7}$. We sought to evaluate with immunoblot analysis whether the expression of key pluripotency transcriptional regulators NANOG, c-MYC, OCT3/4, KLF4, BMI-1 and ALDH1A1 were altered because of HDAC inhibition by $\mathrm{NaB}$. Both SK-ES 1 and RD-ES cells showed a 2-3-fold reduction in the levels of pluripotency-associated genes OCT3/4, c-MYC and BMI-1 compared to untreated control cells. The levels of KLF4, NANOG and ALDH1A1 decreased in SK-ES 1 cells but were relatively unchanged or increased in RD-ES cells (Fig. 5A, B). Thus, SK-ES 1 cells show higher sensitivity to $\mathrm{NaB}$ regarding suppression of pluripotency-associated genes.

Interestingly, both EWS cell lines exposed to $\mathrm{NaB}$ showed an approximately 2-fold increase in complexity or granularity measured by the SSC-A mean parameter in flow cytometry (Fig. 6A, B). This alteration was accompanied by cell morphology changes with formation of neurite extensions (Fig. 6C). Furthermore, we assessed the expression level of the neural differentiation marker $\beta$-III Tubulin (TUBB3) (Fig. 6D). We observed an increase in TUBB3 in cells exposed to HDAC activity inhibition by $\mathrm{NaB}$, with a 2 -fold enhancement in protein levels compared to controls. These findings suggest that HDAC activity inhibition may act to suppress a set of genes related to pluripotency, promoting neural differentiation of EWS cells.

\section{HDAC inhibition impairs EWS tumorsphere formation}

Cancer stem cells displaying tumor-initiating properties and treatment resistance ability have been identified and characterized in $\mathrm{EWS}^{27}$. Tumorsphere (TS)-forming assays have been widely used as models to study cancer stem cell-enriched cultures ${ }^{28}$. To verify whether HDAC inhibition altered TS-forming ability of EWS in vitro, we measured TS-formation efficiency (TFE) and size through optical microscopy after exposure of cells to NaB in a serum-free TS-inducing medium for 7 days. HDAC inhibition by $\mathrm{NaB}$ significantly reduced TFE in both EWS cell lines. In addition, $\mathrm{NaB}$ reduced the size of EWS tumorspheres (Fig. 7). It is noteworthy that the higher dose of $\mathrm{NaB}(5 \mathrm{mM})$ fully impaired the cells' ability to produce tumorspheres. These findings suggest that HDis can decrease the ability of EWS 
cancer stem cells to expand and survive, thus revealing HDAC as a potential novel EWS cancer stem cell target.

\section{Discussion}

Inhibition of HDAC activity has become an increasingly promising therapeutic strategy given its potential to ameliorate the aberrant epigenetic state that underlies a variety of cancers and allows the expression of silenced genes that can promote cell death or differentiation. We found that $\mathrm{NaB}$ efficiently inhibits HDAC global activity in EWS cells, along with cell growth, long-term proliferation, and colony formation. Similar $\mathrm{IC}_{50}$ values for HDAC inhibition and cell growth impairment were observed in both cell lines, leading to G1-phase accumulation. These findings support previous reports of $\mathrm{NaB}$ arresting cell cycle, particularly at G1-phase, and inducing cell differentiation and apoptosis in multiple cell lines $^{29-31}$. The overexpression of cyclins D (cyclin D1, D2, and D3) can drive aberrant cell cycle regulation and signaling in many human malignant tumors, including EWS tumors and RD-ES cells ${ }^{32,33}$. Inhibition of HDAC by NaB resulted in a decrease of cyclin D1 protein level in both cell lines, similarly to what was previously reported in neuroblastoma ${ }^{34}$. The expression level of cyclin D1, a G1- phase regulator protein, may represent an important component that controls growth arrest prior to cell differentiation in EWS cells.

Polyploidy induction is a proposed mechanism by which HDis control tumor cell growth. For instance, SAHA induced polyploidy in human colon cancer and breast cancer cells, leading to senescence, particularly in cells harboring defective p21WAF1 or $\mathrm{p} 53^{35}$. In contrast, we observed a significant reduction in the proportion of cells showing polyploidy after $\mathrm{NaB}$ exposure. HDAC inhibition induced changes in pathways related to cell proliferation and survival in EWS cells, including components of neurotrophin signaling. In other types of pediatric and neuroendocrine cancers, differential neurotrophin and Trk expression is associated with patient prognosis and tumor properties including angiogenesis, metastasis, and chemosensitivity ${ }^{36}$. In EWS, we have recently shown the expression of Trk in tumors, and that Trk inhibition reduced cell growth and increased chemosensitivity ${ }^{37}$. Here we show that $\mathrm{NaB}$ exposure in EWS cells resulted in a reduced NGF and BDNF protein levels, which is accompanied by reductions in components of the ERK and AKT pathways.

Given that neurotrophins are known to mediate neuronal survival via activation of ERK, phosphatidylinositol 3-kinase (PI3K) and phospholipase $\mathrm{C} \gamma(\mathrm{PLC}-\gamma)^{38}$, which supports our hypothesis that the inhibition of global HDAC activity suppresses Trk-mediated survival pathways in EWS cells.

We also observed a NaB-induced decrease in the levels of the mitotic marker $\mathrm{H} 3$ phos-S10. During mitosis in late $\mathrm{G} 2$ and $\mathrm{M}$ phase of cell cycle, the post-translational modification phosphorylation on serine 10 of histone 3 (H3 phos-S10) is taken as a hallmark of condensed chromatin ${ }^{39}$. High levels of $\mathrm{H} 3$ phos-S10 in oncogene-transformed cells and human cancer cells are associated with amplified activation of the Ras-Mitogen-activated protein kinase (MAPK)-MSK1 pathway ${ }^{40}$. Moreover, H3 phos-S10 overexpression is associated with chromosome instability that plays a role in the maintenance of ploidy ${ }^{41}$ and 
carcinogenesis ${ }^{42}$. There is a crucial role of phosphorylation on serine 10 of histone 3 at the p21 promoter to activate $\mathrm{p} 21$ gene through HDAC inhibition by trichostatin $\mathrm{A}^{43}$.

Carcinogenesis mediated by cancer stem cells may be considered a sort of epigenetic reprograming where there is loss of expression of specific genes that control differentiation and reactivation of genes specifying stemness ${ }^{44}$. Consistent with this rationale, our results showed that HDAC inhibition potently suppresses pluripotency-associated genes and this is associated with neurite outgrowth and expression of the neuronal differentiation marker $\beta$-III tubulin. A microarray analysis report revealed that HDAC inhibition by TSA suppresses pluripotency genes including as Nanog, Klf4, Sox 2 and Sall4 in embryonic stem cells while activating differentiation-related genes ${ }^{45}$. $\beta$-III tubulin is a neuron-specific marker and is expressed in early postmitotic and differentiated neurons ${ }^{46}$, hence this differentiation neuronal marker has been used to evaluate neural differentiation in $\mathrm{EWS}^{47,48}$. Our findings support the possibility that $\mathrm{NaB}$ can reprogram EWS cells towards neural differentiation.

Sphere formation in cancer cell cultures is a widely used platform for cancer stem cell expansion. Cells from tumorspheres had higher levels of pluripotency-related genes such as Oct3/4 and BMI-1, supporting a stem cell phenotype. In addition, tumorspheres showed higher levels of TrkB compared to cells grown in monolayer, suggesting a possible increase in neurotrophin signaling in EWS stem cells ${ }^{49}$. Importantly, $\mathrm{NaB}$ reduced sphere formation, indicating that it is capable of targeting EWS stem cells.

Mechanisms other than histone acetylation may be involved in the effects of $\mathrm{NaB}$ in cancer cells. Histone lysine butyrylation is another type of epigenetic post-translational mark that can cooperate or compete with acetylation to promote gene expression programs ${ }^{50-52}$. Increases in butyrylation in neuroblastoma cells after exposure to SAHA have been reported $^{53}$. It should also be noted that $\mathrm{NaB}$ has been shown to enhance cAMP levels and stimulate the activation of multiple protein kinase pathways through mechanisms at least partially mediated by effects independent of epigenetic influences, through direct interactions with cAMP/PKA signaling in the cytoplasm ${ }^{54-56}$. Thus, we cannot exclude the possibility that NaB-induced effects on cell machinery components other than HDACs are involved in our findings.

A schematic model of the biological actions of $\mathrm{NaB}$ in EWS is depicted in Fig. 8. This model proposes a mechanism by which $\mathrm{NaB}$ acts through HDAC inhibition on transcriptional regulators to change the differentiation status of EWS cells. Together our results indicate that HDIs can reduce EWS growth and survival and lead to a differentiated state, thus representing a potentially useful strategy to treat EWS tumors.

\section{Materials and Methods}

\section{Cell lines and cell culture}

Human Ewing sarcoma cell lines SK-ES-1 and RD-ES-1 obtained from American Type Culture Collection (Rockville, MD, USA) were grown in RPMI- 1640 medium (Gibco-BTL, Carlsbad, CA, USA), containing $0.1 \%$ fungizone ${ }^{\circledR}(250 \mathrm{mg} / \mathrm{kg}$; Invitrogen Life Technologies, São Paulo, Brazil), 4 mg/ml gentamicin and 10\% fetal bovine serum (FBS, 
Gibco® by Thermo Fisher Scientific, Life Technologies, Brazil). Cells were cultured at $37^{\circ} \mathrm{C}$ in a humidified incubator under $5 \% \mathrm{CO}_{2}$.

\section{Drug treatment}

Sodium butyrate $(\mathrm{NaB})$ (Sigma Aldrich - St. Louis, MO, USA) was diluted in sterile ultrapure water in a stock solution of $100 \mathrm{mM}$. EWS cells $\left(2 \times 10^{4}\right)$ were plated in 24 -well plate and exposed to $\mathrm{NaB}$ in concentrations ranging from 0.5 to $5 \mu \mathrm{M}$ for $72 \mathrm{~h}^{57}$. For calculation of $\mathrm{IC}_{50}$, data were fitted in a dose response curve (Graphpad Prism v. 6.0) using the equation: $y=\min +(\max -\min ) /\left(1+10^{\wedge}((\log I C 50-x) *\right.$ Hillslope $+\log ((\max -\min ) /$ $(50-\min )-1))$ ).

\section{Cell viability}

Cells were exposed to $\mathrm{NaB}$ as described above. Both cells in the supernatant and adhered cells were detached, collected, centrifuged and washed with PBS twice. To assess viability, cells were incubated with $1 \mu \mathrm{g} / \mathrm{ml}$ propidium iodide (PI) (Sigma Aldrich) in PBS at $4{ }^{\circ} \mathrm{C}$ in the dark. PI uptake was assessed by flow cytometry analysis using an Attune Acoustic focusing cytometer (Applied Biosystems, Thermo Fisher Scientific, USA). Data was analyzed using Attune Cytometric Software version 1.2.5. Four individual replicates were performed.

\section{Cell cycle}

To assess cell cycle, the EWS cells were cultured in 24-well plates under the same conditions of described above, and then detached, centrifuged and washed with PBS twice. After, the cells were ressuspended in $50 \mu \mathrm{g} / \mathrm{ml}$ propidium iodide (Sigma-Aldrich, St. Louis, Mo., USA) in $0.1 \%$ Triton X-100 in $0.1 \%$ sodium citrate solution containing $5 \mu \mathrm{g} / \mathrm{ml}$ RNase A. One million cells were stained in $1.0 \mathrm{ml}$ of the PI cell cycle solution for $5 \mathrm{~min}$. followed by assessment on an Attune Acoustic focusing cytometer by Applied Biosystems (Thermo Fisher Scientific, USA) analysis. In each sample 20,000 cells were analysed. Data was analyzed using FlowJo Cytometric Software version 10.1. Three individual experiments were performed.

\section{Cumulative population doubling}

Cells were plated $\left[2 \times 10^{4}\right.$ cell $\left./ \mathrm{mL}\right]$ and exposed to $\mathrm{NaB}$, in the same conditions described above, in quadruplicates. Every 4 days, supernatant and adhered cells were collected, quantified by PI uptake and re-plated. The Population Doubling (PD) level was calculated to determine the proliferation potential of the cell lines SK-ES 1 and RD-ES unexposed versus $\mathrm{NaB}$ exposed cells. The PD at each passage was calculated using the equation $\mathrm{PD}=(\log \mathrm{Xe}$ $-\log \mathrm{Xb}) / \log 2$ and doubling time was calculated using $\mathrm{DT}=\mathrm{T}^{*} \ln 2 / \ln (\mathrm{Xe} / \mathrm{Xb})$. In both cases ' $\mathrm{Xe}$ ' is the cell number at the end of the incubation time, ' $\mathrm{Xb}$ ' is the cell number at the beginning of the incubation time and $\mathrm{T}$ is the number of days between time points, as described in the ATCC ${ }^{\circledR}$ Animal Cell Culture Guide. Data is displayed as cumulative PD (CPD), calculated as the sum of all previous PDLs.

All the CPD parameters were analyzed according to Silva and colleagues ${ }^{26}$. Briefly, Relative end CPD (RendCPD) quantifies the end point of cell proliferation analysis, and is obtained 
by the ratio between the final CPD of cells exposed to drug and control cells. To determine the global effect after the treatment intervention, the relative Area Under Curve (rAUC) was calculated (Graphpad Prism v. 6.0 software) using the lower CPD of the initial population to obtain the minimal threshold. RPR (Relative Proliferation Rate) and RTCT (Relative Time to Cross a Threshold), linear regression for both exposed and control groups was calculated using the higher angular coefficients of the last two or more CPD intervals. RPR is the ratio of the angular coefficients of exposed and control groups. RTCT was determined by the ratio of between the control and exposed cells Time to Cross the Threshold (TCT), i.e., a threshold set on a CPD value where both treatment and control conditions present the highest velocity of proliferation. Long-term survival index (LSI) is calculated by the average of the four parameters described above.

\section{Colony formation}

Cells were exposed to $\mathrm{NaB}$ for $72 \mathrm{~h}$ and $1 \times 10^{2}$ cells per well were re-plated in 6-well plates and cultured for 10 days with the RPMI medium being changed every 3 days. Cells were then fixed with methanol, followed by staining with $0.5 \%$ crystal violet. The stained colonies images were scanned and analyzed using the cell counter plugin on Image $\mathbf{J}$ software (NIH, Bethesda, MD, USA).

\section{Tumorsphere culture}

Cells were dissociated with trypsin-EDTA into single cell suspension and seeded at $2 \times 10^{3}$ cells/well in 6-well plates. The cells were cultured in a serum-free tumorsphere (TS)inducing medium, containing DMEM-F12 (1:1) supplemented with 2\% B27 supplement (Gibco, Invitrogen, CA, USA), $20 \mathrm{ng} / \mathrm{mL}$ recombinant human EGF (Sigma-Aldrich, MO, USA), $20 \mathrm{ng} / \mathrm{mL}$ human leukemia inhibitor factor (Thermo Fisher Scientific, Life Technologies), $10 \mathrm{IU} / \mathrm{mL}$ ( $5 \mathrm{mg} / \mathrm{mL}$ ) heparin (Roche, Mannheim, Germany) and antibiotics as described by Leuchte and colleagues ${ }^{58}$. The media was changed every 4 days. After $8-9$ days, tumorspheres were dissociated with a non-enzymatic solution containing $1 \mathrm{mM}$ EDTA, $40 \mathrm{mM}$ Tris- $\mathrm{HCl}$ and $150 \mathrm{mM} \mathrm{NaCl}$, and re-plated in a 96-well plate to evaluate their capacity to self-renew through secondary EWS tumorsphere formation. Tumorspheres with at least $80 \mu \mathrm{m}$ were analyzed and quantified by inverted phase microscopy (Leica Microsystems, Mannheim Germany). The effect of $\mathrm{NaB}$ on tumorsphere formation ability during 7 days was examined.

\section{HDAC activity}

Cells $\left(1 \times 10^{4}\right)$ were seeded in a 96 black well plate/clear flat-bottom (Greiner-bioone, Frickenhausen, $\mathrm{DE}$ ) and exposed to $\mathrm{NaB}$, at the same concentrations described above, for 1 or $3 \mathrm{~h}$. HDAC enzymatic activity was measured by In Situ HDAC Activity Fluorometric Assay kit (EPI003, Sigma-Aldrich, St. Louis, MO, USA) according to the manufacturer's instructions. Three individual experiments were performed. HDAC enzyme activity was calculated across the groups as $\mathrm{pmol} / \mathrm{min}$ and the percent of HDAC activity was corrected by control (unexposed cells). 


\section{Immunofluorescence}

For immunofluorescent staining, cells were plated on the glass coverslips, pre-coated with 2 $\mu \mathrm{g} / \mathrm{ml}$ of fibronectin. After $72 \mathrm{~h}$ of exposure to $\mathrm{NaB}$, cells were fixed in 4\% PFA for 15 minutes at room temperature. After two additional washes, the fixed cells were incubated with blocking buffer (1X PBS containing 3\% BSA and $0.3 \%$ Triton X-100) for $1 \mathrm{~h}$ at room temperature, followed by an overnight incubation at $4{ }^{\circ} \mathrm{C}$ with the following primary antibodies: Histone 3 phos-S10 (1:200, Cell Signaling), Trkb (1:100, Santa Cruz). After washing with PBS twice, cells were incubated with secondary antibodies conjugated with either Alexa fluor-488 (1:800; Invitrogen) or Rhodamine (1:300, Invitrogen) at room temperature for two h. After three additional washes, DNA was stained with $4 \mu \mathrm{g} / \mathrm{ml}$ of Hoechst 33342 (Invitrogen) for 15 minutes at room temperature. After washing, slides were mounted with Prolong Gold anti-fade reagent. Slides were viewed with Leica TCS SP5 Confocal Laser Scanning Microscope, using Leica LAS AF Lite 2.0.2 software to acquire images. For quantitative analysis, was calculated by the percent of mean intensity corrected by the control (unexposed cells). For each group, at least five random images were taken, and the results were determined from at least three independent experiments.

\section{Real time qPCR}

Total RNA was extracted from EWS cells using TRIzol (Invitrogen, Carlsbad, CA, USA). Prior to RT-PCR, the samples were treated with DNase I (Promega Corporation, WI, USA). Total RNA was quantified with NanoDrop (Thermo Fisher Scientific, DE, USA). SuperScript ${ }^{\mathrm{TM}}$ First-Strand Synthesis System for RT-PCR (Invitrogen, Carlsbad, CA, USA) enabled first strand synthesis. Expression of target genes (TrkB and Oct3/4) were quantified using KiCqStart ${ }^{\mathrm{TM}}$ SYBR Green qPCR ReadyMix ${ }^{\mathrm{TM}}$, with ROX ${ }^{\mathrm{TM}}$ (Sigma-Aldrich, St. Louis, MO, USA) and normalized to the expression of Gapdh (housekeeping gene). The primer sequences used are shown in Supplementary Table S1 online.

\section{Western blot}

Proteins were separated using $8-14 \%$ SDS Tris-glycine gels and transferred onto a polyvinylidene difluoride membranes. Membranes were blocked with 5\% fat-free milk and incubated with antibodies against BDNF (H117, SC-20981, Santa Cruz, CA, USA), NGF (H-20, sc-548, Santa Cruz, CA, USA), pERK (E-4 sc-7383, Santa Cruz, CA, USA), ERK1 (K-23, sc-94, Santa Cruz, CA, USA), pAKT (S473) (SAB4300042, Sigma Aldrich, MO, USA), AKT (pan) (C67E7, \#4691, Cell Signaling Technology, MA, USA), OCT3/4 (sc-5279, Santa Cruz, CA, USA), NANOG (M-149, sc-33760, Santa Cruz, CA, USA), cMYC (D84C12 - Cell Signaling Technology, MA, USA), KLF4 (H-180, SC-20691, Santa Cruz, CA, USA), ALDH1A1 (ab23375, Abcam, Cambridge, UK), BMI-1 (D20B7, \#6964 Cell Signaling Technology, MA,USA), Cyclin D1 (D71G9 - Cell Signaling Technology, MA, USA), $\beta$ III-Tubulin (D71G9 - Cell Signaling Technology, MA,USA) and ACTB (A2228, Sigma Aldrich, MO, USA) used as loading control. Incubation with appropriate horsedish peroxidase-conjugated secondary antibody (Santa Cruz) for $1 \mathrm{~h}$ at RT was performed. Chemiluminescence was detected using ECL Western Blotting substrate (EMD Millipore, DE) and analyzed by ImageQuant LAS500 (GE Healthcare Life Sciences, UK). Densitometric analyses were performed using Image J (NIH, MD, USA). Relative 
densitometric unit (RDU) was calculated by the normalization of interest protein level to the housekeeping genes $\beta$-actin (ACTB) or Histone 3 (H3) and corrected by control (unexposed cells). Three individual replicates were performed.

\section{Statistical analysis}

For statistical analysis, GraphPad Prism version 6.0 was used. Each assay was performed at least three times in biologically independent assays. The significance of differences in mean \pm standard error values was analyzed by one-way ANOVA and Tukey's multiple comparison test or Student's t-test; $\mathrm{p}$ values of less than 0.05 were considered statistically significant.

\section{Supplementary Material}

Refer to Web version on PubMed Central for supplementary material.

\section{Acknowledgements}

This research was supported by the PRONON/Ministry of Health, Brazil (number 25000.162.034/2014-21); the Rafael Koff Acordi Research Center, Children's Cancer Institute (ICI); the National Council for Scientific and Technological Development (CNPq; grant number 303276/2013-4 to R.R.); the Coordination for the Improvement of Higher Education Personnel (CAPES; to B.K.S.); the Clinical Hospital institutional research fund (FIPE/HCPA); and the Center for Cancer Research, National Cancer Institute, National Institutes of Health (C.J.T.).

\section{References}

1. Balamuth NJ \& Womer RB Ewing's sarcoma. Lancet Oncol 11, 184-192 (2010). [PubMed: 20152770]

2. Gaspar $\mathrm{N}$ et al. Ewing sarcoma: Current management and future approaches through collaboration. $\mathrm{J}$ Clin Oncol 33, 3036-3046 (2015). [PubMed: 26304893]

3. Ross KA, Smyth NA, Murawski CD \& Kennedy JG The biology of ewing sarcoma. ISRN Oncol 2013, 759725 (2013). [PubMed: 23346417]

4. Cavazzana AO, Miser JS, Jefferson J \& Triche TJ Experimental evidence for a neural origin of Ewing's sarcoma of bone. Am J Pathol 127, 507-518 (1987). [PubMed: 3035930]

5. Parham DM et al. Neuroectodermal differentiation in ewing's sarcoma family of tumors does not predict tumor behavior. Hum Pathol 30, 911-918 (1999). [PubMed: 10452503]

6. Staege MS et al. DNA microarrays reveal relationship of Ewing family tumors to both endothelial and fetal neural crest-derived cells and define novel targets. Cancer Res 64, 8213-8221 (2004). [PubMed: 15548687]

7. von Levetzow $\mathrm{C}$ et al. Modeling initiation of ewing sarcoma in human neural crest cells. PLoS One 6, 1-10 (2011).

8. Miyagawa $\mathrm{Y}$ et al. Inducible expression of chimeric EWS/ETS proteins confers Ewing's family tumor-like phenotypes to human mesenchymal progenitor cells. Mol Cell Biol 28, 2125-2137 (2008). [PubMed: 18212050]

9. Riggi N et al. Development of Ewing's sarcoma from primary bone marrow-derived mesenchymal progenitor cells. Cancer Res 65, 11459-11468 (2005). [PubMed: 16357154]

10. Riggi $\mathrm{N}$ et al. EWS-FLI-1 expression triggers a ewing's sarcoma initiation program in primary human mesenchymal stem cells. Cancer Res 68, 2176-2185 (2008). [PubMed: 18381423]

11. Tirode F et al. Mesenchymal stem cell features of Ewing tumors. Cancer Cell 11, 421-429 (2007). [PubMed: 17482132]

12. Crompton BD et al. The genomic landscape of pediatric Ewing sarcoma. Cancer Discov 4, 13261341 (2014). [PubMed: 25186949] 
13. Riggi $\mathrm{N}$ et al. EWS-FLI1 utilizes divergent chromatin remodeling mechanisms to directly activate or repress enhancer elements in Ewing sarcoma. Cancer Cell 26, 668-681 (2014). [PubMed: 25453903]

14. Gomez NC, et al. Widespread chromatin accessibility at repetitive elements links stem cells with human cancer. Cell Rep 17, 1607-1620 (2016). [PubMed: 27806299]

15. Sankar S et al. Reversible LSD1 inhibition interferes with global EWS/ETS transcriptional activity and impedes Ewing sarcoma tumor growth. Clin Cancer Res 20, 4584-4597 (2014). [PubMed: 24963049]

16. Ban J et al. Suppression of deacetylase SIRT1 mediates tumor-suppressive NOTCH response and offers a novel treatment option in metastatic Ewing sarcoma. Cancer Res 74, 6578-6588 (2014). [PubMed: 25281719]

17. Lawlor ER \& Thiele CJ Epigenetic changes in pediatric solid tumors: Promising new targets. Clin Cancer Res 18, 2768-2779 (2012). [PubMed: 22589485]

18. Kouzarides T Chromatin modifications and their function. Cell 128, 693-705 (2007). [PubMed: 17320507]

19. Bolden JE, Peart MJ \& Johnstone RW Anticancer activities of histone deacetylase inhibitors. Nat Rev Drug Discov 5, 769-784 (2006). [PubMed: 16955068]

20. Mottamal M, Zheng S, Huang TL \& Wang G Histone deacetylase inhibitors in clinical studies as templates for new anticancer agents. Molecules 20, 3898-3941 (2015). [PubMed: 25738536]

21. Candido EPM, Reeves R \& Davie JR Sodium butyrate inhibits histone deacetylation in cultured cells. Cell 14, 105-113 (1978). [PubMed: 667927]

22. Dos Santos MP, de Farias CB, Roesler R, Brunetto AL \& Abujamra AL In vitro antitumor effect of sodium butyrate and zoledronic acid combined with traditional chemotherapeutic drugs: A paradigm of synergistic molecular targeting in the treatment of Ewing sarcoma. Oncol Rep 31, 955-968 (2014). [PubMed: 24316794]

23. Unland R et al. Suberoylanilide hydroxamic acid synergistically enhances the antitumor activity of etoposide in Ewing sarcoma cell lines. Anticancer Drugs 26, 843-851 (2015). [PubMed: 26053276]

24. Sonnemann $\mathrm{J}$ et al. Histone deacetylase inhibitors induce cell death and enhance the apoptosisinducing activity of TRAIL in Ewing's sarcoma cells. J Cancer Res Clin Oncol 133, 847-858 (2007). [PubMed: 17486365]

25. Hans F \& Dimitrov S Histone H3 phosphorylation and cell division. Oncogene 20, 3021-3027 (2001). [PubMed: 11420717]

26. Silva AO, Felipe KB, Villodre ES, Lopez PLC \& Lenz G A guide for the analysis of long-term population growth in cancer. Tumour Biol 37, 13743-13749 (2016). [PubMed: 27476170]

27. Suvà ML et al. Identification of cancer stem cells in Ewing's sarcoma. Cancer Res 69, 1776-1781 (2009). [PubMed: 19208848]

28. Pastrana E, Silva-Vargas V \& Doetsch F Eyes wide open: a critical review of sphere-formation as an assay for stem cells. Cell Stem Cell 8, 486-498 (2011). [PubMed: 21549325]

29. Barnard JA \& Warwick G Butyrate rapidly induces growth inhibition and differentiation in HT-29 cells. Cell Growth Differ 4, 495-501 (1993). [PubMed: 8373733]

30. Archer SY, Meng S, Shei a \& Hodin R. a. p21 (WAF1) is required for butyrate-mediated growth inhibition of human colon cancer cells. Proc Natl Acad Sci U S A 95, 6791-6796 (1998). [PubMed: 9618491]

31. Jiang W et al. Dual effects of sodium butyrate on hepatocellular carcinoma cells. Mol Biol Rep 39, 6235-6242 (2012). [PubMed: 22228088]

32. Hunter T \& Pines J Cyclins and Cancer.2. Cyclin-D and Cdk Inhibitors Come of Age. Cell 79, 573-582 (1994). [PubMed: 7954824]

33. Zhang J, Hu S, Schofield DE, Sorensen PHB \& Triche TJ Selective usage of D-Type cyclins by Ewing's tumors and rhabdomyosarcomas. Cancer Res 64, 6026-6034 (2004). [PubMed: 15342383]

34. Lorenz V et al. Sodium butyrate induces cellular senescence in neuroblastoma and prostate cancer cells. Horm Mol Biol Clin Investig 7, 265-272 (2011). 
35. Xu WS, Perez G, Ngo L, Gui CY \& Marks PA Induction of polyploidy by histone deacetylase inhibitor: a pathway for antitumor effects. Cancer Res 65, 7832-7839 (2005). [PubMed: 16140952]

36. Thiele CJ, Li Z \& McKee AE On Trk - the TrkB signal transduction pathway is an increasingly important target in cancer biology. Clin Cancer Res 15, 5962-5967 (2009). [PubMed: 19755385]

37. Heinen TE et al. Trk inhibition reduces cell proliferation and potentiates the effects of chemotherapeutic agents in Ewing sarcoma. Oncotarget 7, 34860-34880 (2016). [PubMed: 27145455]

38. Reichardt LF Neurotrophin-regulated signalling pathways. Philos Trans R Soc B Biol Sci 361, 1545-1564 (2006).

39. Hans F \& Dimitrov S Histone H3 phosphorylation and cell division. Oncogene 20, 3021-3027 (2001). [PubMed: 11420717]

40. Strelkov IS, \& Davie JR \& Ser-10 phosphorylation of histone H3 and immediate early gene expression in oncogene-transformed mouse fibroblasts. Cancer Res 62, 75-78. (2002). [PubMed: 11782362]

41. Ota $\mathrm{T}$ et al. Increased mitotic phosphorylation of histone $\mathrm{H} 3$ attributable to AIM-1/Aurora-B overexpression contributes to chromosome number instability. Cancer Res 62, 5168-5177 (2002). [PubMed: 12234980]

42. Espino PS, Pritchard S, Heng HHQ \& Davie JR Genomic instability and histone H3 phosphorylation induction by the Ras-mitogen activated protein kinase pathway in pancreatic cancer cells. Int J Cancer 124, 562-567 (2009). [PubMed: 19004007]

43. Simboeck E et al. A phosphorylation switch regulates the transcriptional activation of cell cycle regulator p21 by histone deacetylase inhibitors. J Biol Chem 285, 41062-41073 (2010). [PubMed: 20952396]

44. Shukla S \& Meeran SM Epigenetics of cancer stem cells: Pathways and therapeutics. Biochim Biophys Acta 1840, 3494-3502 (2014). [PubMed: 25240776]

45. Karantzali E et al. Histone deacetylase inhibition accelerates the early events of stem cell differentiation: transcriptomic and epigenetic analysis. Genome Biol 9, R65 (2008). [PubMed: 18394158]

46. Yang HKC et al. Distribution of doublecortin expressing cells near the lateral ventricles in the adult mouse brain. J Neurosci Res 76, 282-295 (2004). [PubMed: 15079857]

47. Rocchi A \& Manara M CD99 inhibits neural differentiation of human Ewing sarcoma cells and thereby contributes to oncogenesis. J Clin Invest 120, 668-680 (2010). [PubMed: 20197622]

48. Ventura S et al. CD99 regulates neural differentiation of Ewing sarcoma cells through miR-34aNotch-mediated control of NF-kB signaling. Oncogene 1-11 (2015).

49. Chopin V, Lagadec C, Toillon R \& Le Bourhis X Neurotrophin signaling in cancer stem cells. Cell Mol Life Sci 73, 1859-1870 (2016). [PubMed: 26883804]

50. Chen $\mathrm{Y}$ et al. Lysine propionylation and butyrylation are novel post-translational modifications in histones. Mol Cell Proteomics 6, 812-819 (2007). [PubMed: 17267393]

51. Choudhary C, Weinert BT, Nishida Y, Verdin E \& Mann M The growing landscape of lysine acetylation links metabolism and cell signalling. Nat Rev Mol Cell Biol. 15, 536-550 (2014). [PubMed: 25053359]

52. Goudarzi A et al. Dynamic competing histone H4 K5K8 acetylation and butyrylation are hallmarks of highly active gene promoters. Mol Cell 62, 169-180 (2016). [PubMed: 27105113]

53. $\mathrm{Xu} \mathrm{G}$ et al. SAHA regulates histone acetylation, butyrylation, and protein expression in neuroblastoma. J Proteome Res 13, 4211-4219 (2014). [PubMed: 25160476]

54. Prasad KN \& Sinha PK Effect of sodium butyrate on mammalian cells in culture: a review. In Vitro 12, 125-132 (1976). [PubMed: 2548]

55. Rivero JA \& Adunyah SE Sodium butyrate induces tyrosine phosphorylation and activation of MAP kinase (ERK-1) in human K562 cells. Biochem Biophys Res Commun 224, 796-801 (1996). [PubMed: 8713125]

56. Rivero JA \& Adunyah SE Sodium butyrate stimulates PKC activation and induces differential expression of certain PKC isoforms during erythroid differentiation. Biochem Biophys Res Commun 248, 664-668 (1998). [PubMed: 9703983] 
57. Nör $\mathrm{C}$ et al. The histone deacetylase inhibitor sodium butyrate promotes cell death and differentiation and reduces neurosphere formation in human medulloblastoma cells. Mol. Neurobiol 48, 533-543 (2013). [PubMed: 23516101]

58. Leuchte $\mathrm{K}$ et al. Anchorage-independent growth of ewing sarcoma cells under serum-free conditions is not associated with stem-cell like phenotype and function. Oncol Rep 32, 845-852 (2014). [PubMed: 24927333] 
a

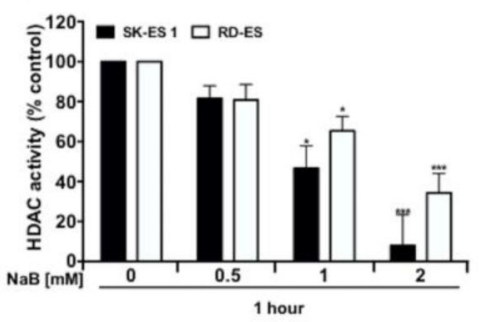

b

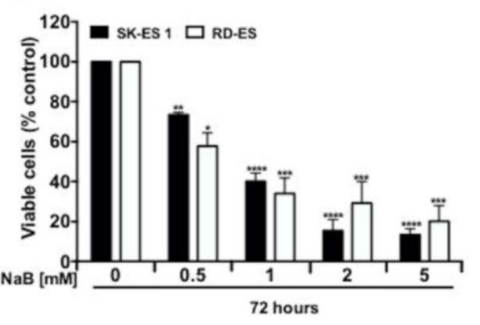

C

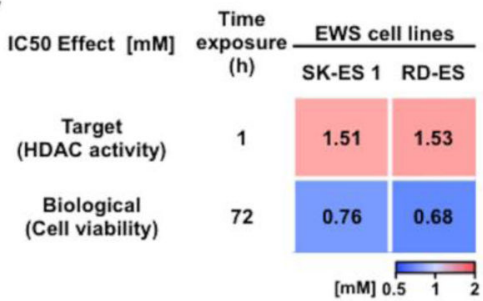

d $\mathrm{NaB}[\mathrm{mM}]$ 0.5
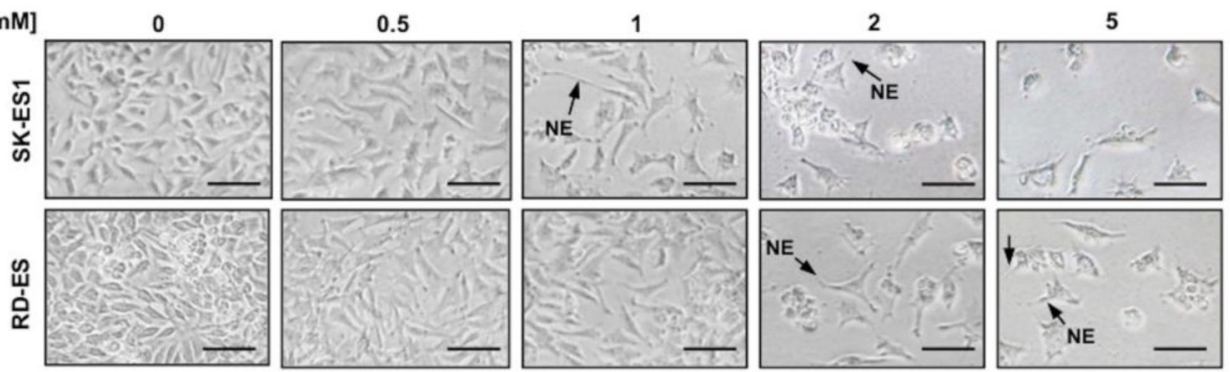

Figure 1. HDAC Inhibition by NaB hinders the growth of EWS cells.

(a) HDAC activity (\%) in EWS cell lines SK-ES 1 and RD-ES after $1 \mathrm{~h}$ of exposure to NaB; $n=4$ independent experiments (b) Percent of viable SK-ES 1 and RD-ES cells after $72 \mathrm{~h}$ of exposure to NaB; $n=4$ independent experiments (c) Heat map showing the target $\mathrm{IC}_{50}$ calculated by the percentage of HDAC activity in cells exposed to $\mathrm{NaB}$ for $1 \mathrm{~h}$, and biological IC50 calculated by the percent of viable cells exposed to $\mathrm{NaB}$ for $72 \mathrm{~h}$. (d) Morphology of EWS SK-ES 1 (upper panel) and RD-ES (lower panel) cells after $72 \mathrm{~h}$ of $\mathrm{NaB}$ exposure; black arrows indicates neurite-like extensions (NE). Scale bar: $50 \mu \mathrm{m}$. Data in the graphs are shown as mean \pm s.e.m.; $* \mathrm{p}<0.05$, ** $\mathrm{p}<0.01$, *** $\mathrm{p}<0.001$, **** $\mathrm{p}<$ 0.0001 vs. controls. 
a

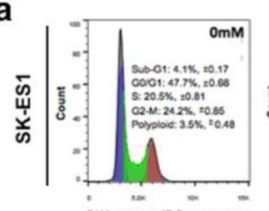

ONA content, IP f fuorescence
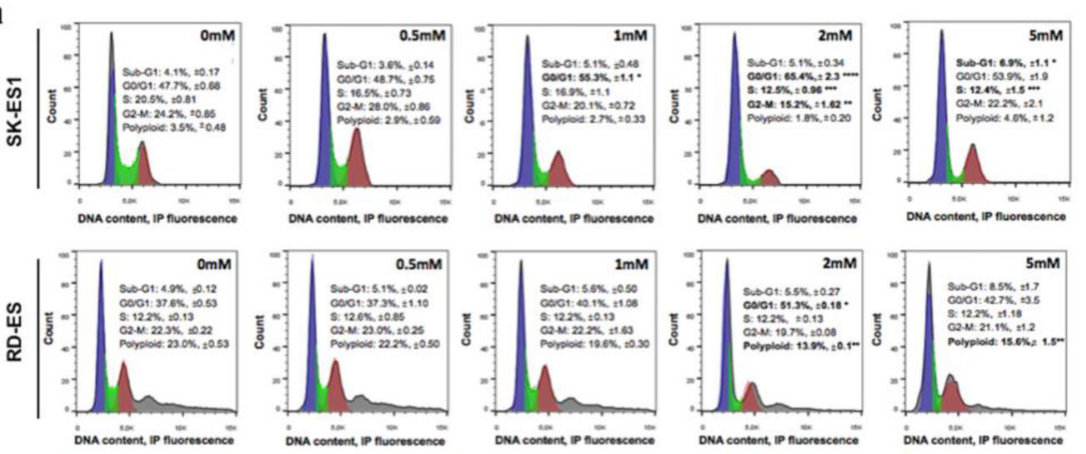

b
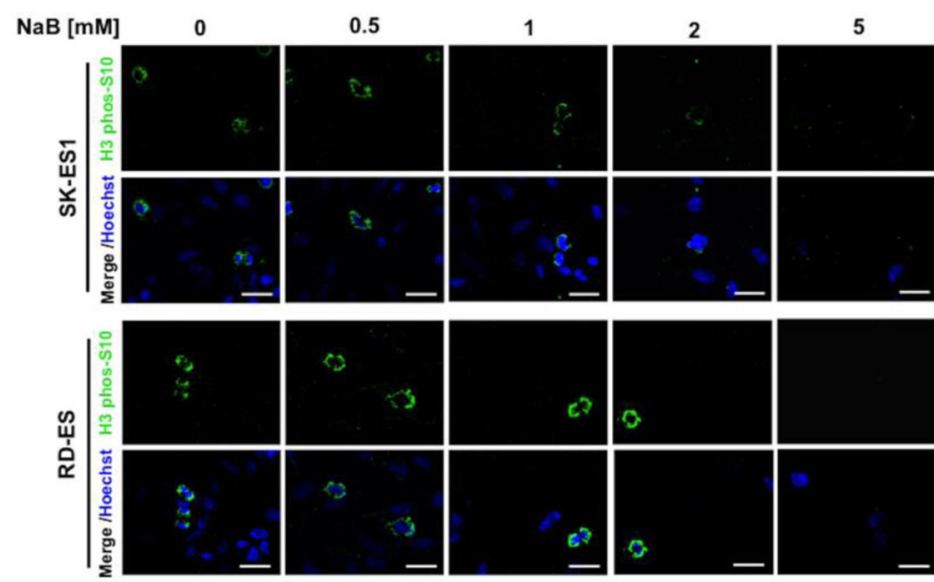

C

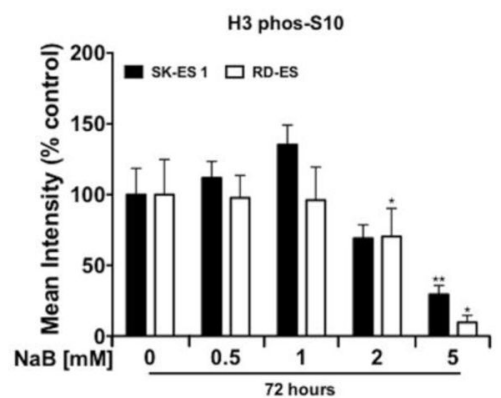

Figure 2. Cell cycle changes induced by HDAC inhibition in EWS cells.

(a) Cell cycle distribution of EWS SK-ES 1 (upper panel) and RD-ES (lower panel) cells after $35 \mathrm{~h}$ of $\mathrm{NaB}$ exposure; $n=3$ independent experiments (b) Representative images of $\mathrm{H} 3$ phos-S10 level (immunofluorescence) from SK-ES 1 (upper panel) and RD-ES (lower panel) cells exposed to $\mathrm{NaB}$ for $72 \mathrm{~h}$. (c) Percent of $\mathrm{H} 3$ phos-S10 mean intensity (immunofluorescence) from EWS cell lines exposed to $\mathrm{NaB}$ for $72 \mathrm{~h} ; n=3$ independent experiments. (d) Western blot (upper panel) of Cyclin D1 protein levels in EWS cells exposed to $\mathrm{NaB}$ for $72 \mathrm{~h}$, and Relative Densitometric Unit (RDU) analysis (lower panel) 
normalized by ACTB, and corrected by control. Data in the graphs are shown as mean \pm s.e.m.; $* \mathrm{p}<0.05, * * \mathrm{p}<0.01,{ }^{* * *} \mathrm{p}<0.001, * * * * \mathrm{p}<0.0001$ vs. controls. 
a

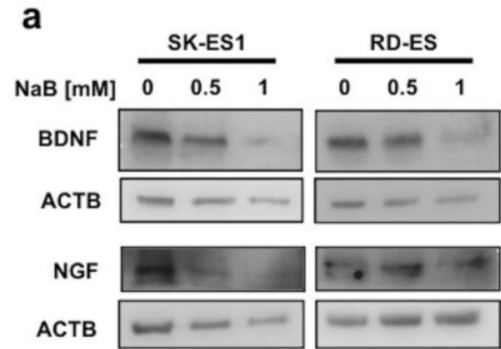

TrkB

b

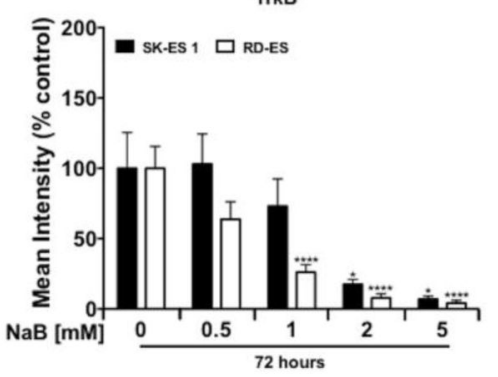

C
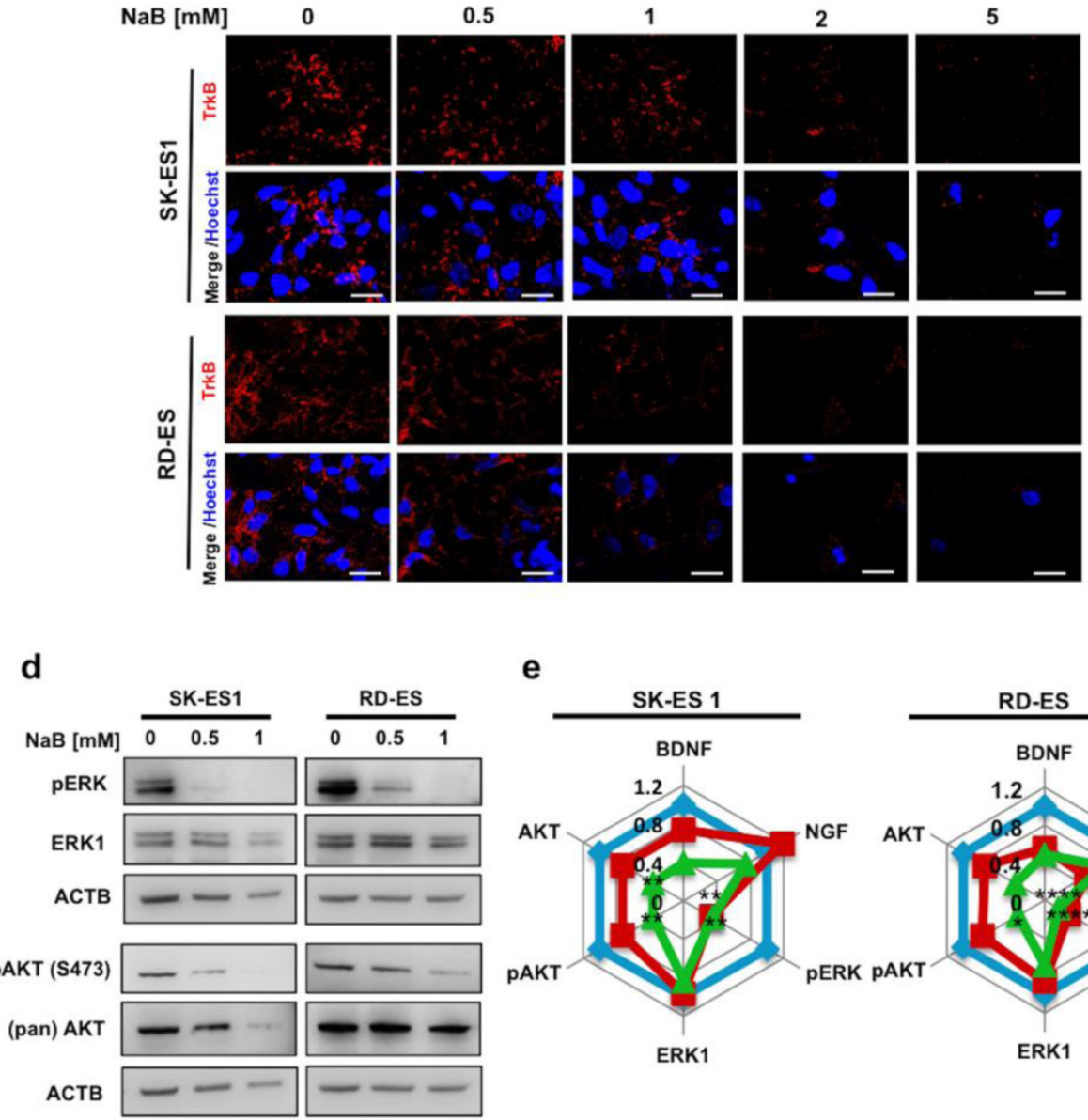

e
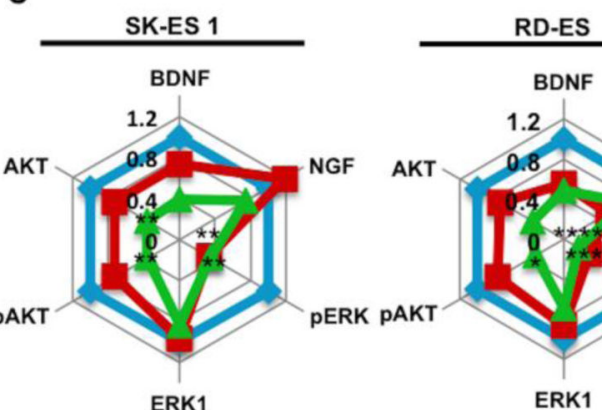

RDNF

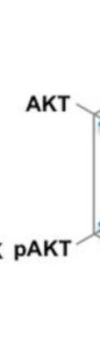

BDNF

1.2

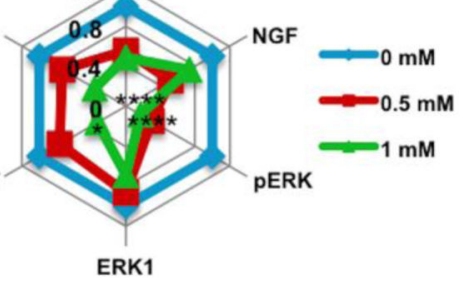

Figure 3. HDAC activity inhibition decreases components of signaling pathways related to proliferation and survival in EWS cells.

(a) Western Blot of BDNF and NGF from SK-ES 1 (left) and RD-ES (right) cells exposed to $\mathrm{NaB}$ for $72 \mathrm{~h}$. (b) Percent of TrkB mean intensity (immunofluorescence). (c) Representative images of TrkB level (immunofluorescence) from SK-ES 1 (upper panel) and RD-ES (lower panel) cells exposed to NaB for 72 h. (d) Western Blot analysis of pERK, ERK1, pAKT(Ser473), AKT in SK-ES 1 (left panel) and RD-ES (right panel) cells. (e) Radar graph showing Relative Densitometric Unit (RDU) analysis were normalized by ACTB, and 
corrected relative to control cells. Data in the graph are shown as mean \pm s.e.m. from three independent experiments; $* \mathrm{p}<0.05, * * \mathrm{p}<0.01, * * * * \mathrm{p}<0.0001$ vs. controls. 
a

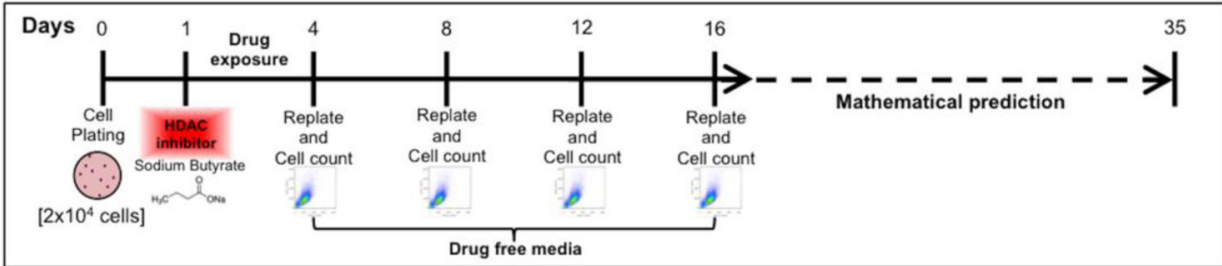

b
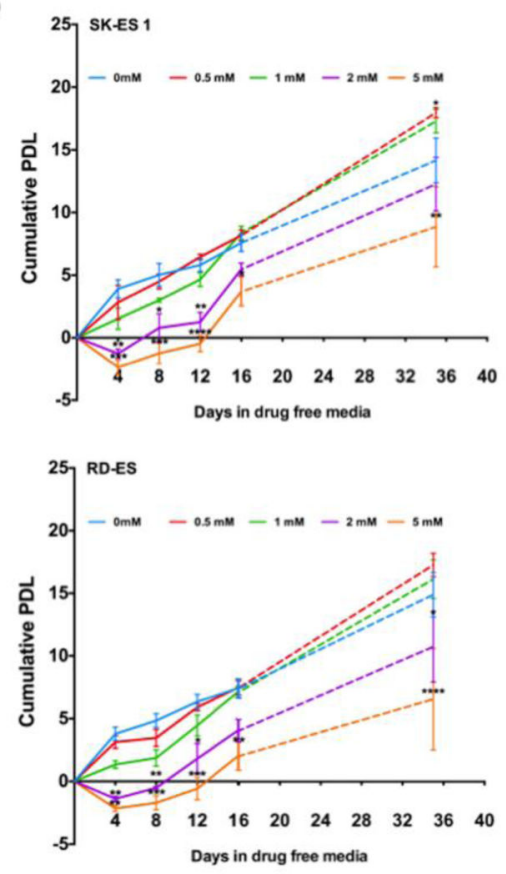

d

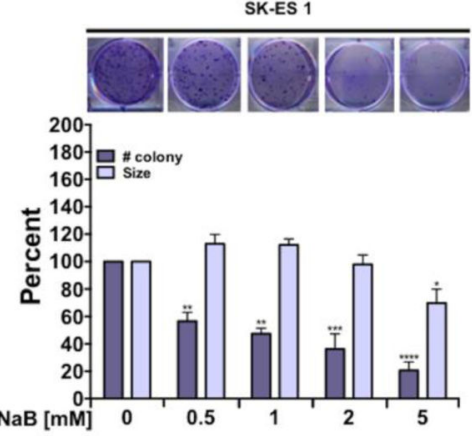

c
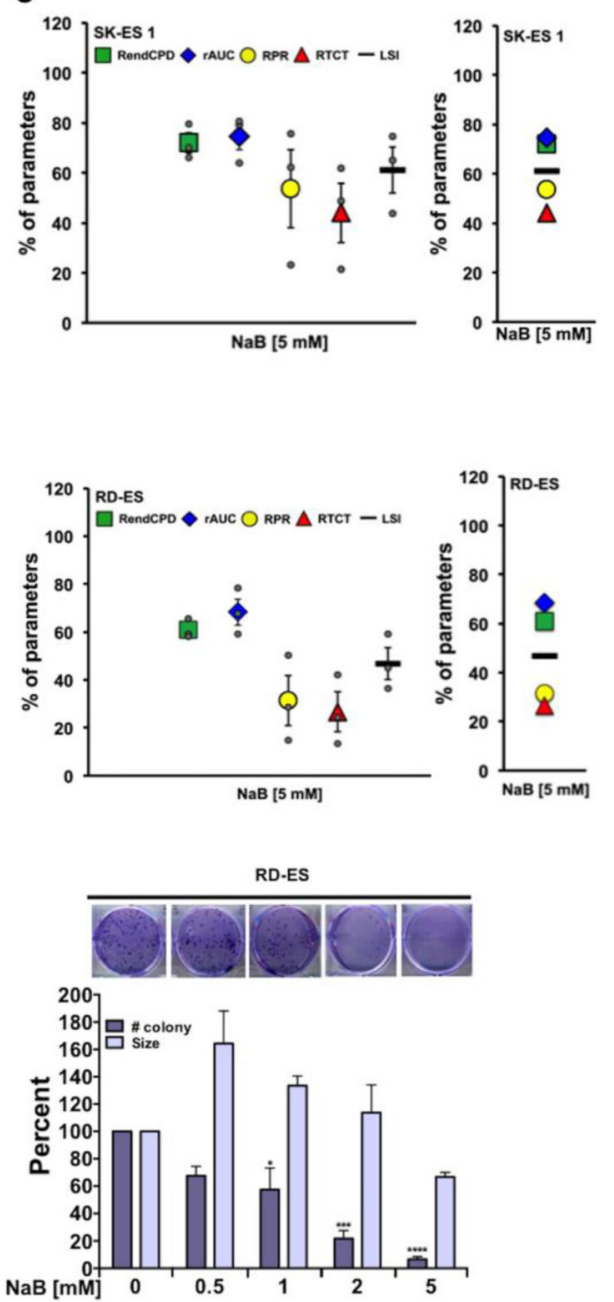

Figure 4. Persistent inhibition of cell proliferation rate and colony formation ability in EWS cells treated with $\mathrm{NaB}$.

(a) Cumulative Population Doubling (CPD) in vitro assay schematic and timeline. (b) Cumulative CPD from SK-ES1 (upper panel) and RD-ES (lower panel) EWS cells after $72 \mathrm{~h}$ of $\mathrm{NaB}$ treatment plus 16 days in a drug free media, plus 19 days of a mathematical prediction (total 35 days); $n=3$ independent experiments. (c) CPD profile from SK-ES1 (upper) and RD-ES (lower) EWS cells after $72 \mathrm{~h}$ of $\mathrm{NaB}(5 \mathrm{mM})$. (Green square RendCPD, Blue diamond - rAUC, yellow circle - RPR, red triangle - RTCT, black line LSI). (d) Colony formation in SK-ES1 (left panel) and RD-ES (right panel) cells after 72h 
of $\mathrm{NaB}$ exposure plus 10 days in a drug free media, measured by percent of colony number and size; $n=3$ independent experiments. Data in the graphs are shown as mean \pm S.E.M; ${ }^{*} \mathrm{p}$ $<0.05, * * \mathrm{p}<0.01, * * * \mathrm{p}<0.001, * * * * \mathrm{p}<0.0001$ vs. controls. 
a

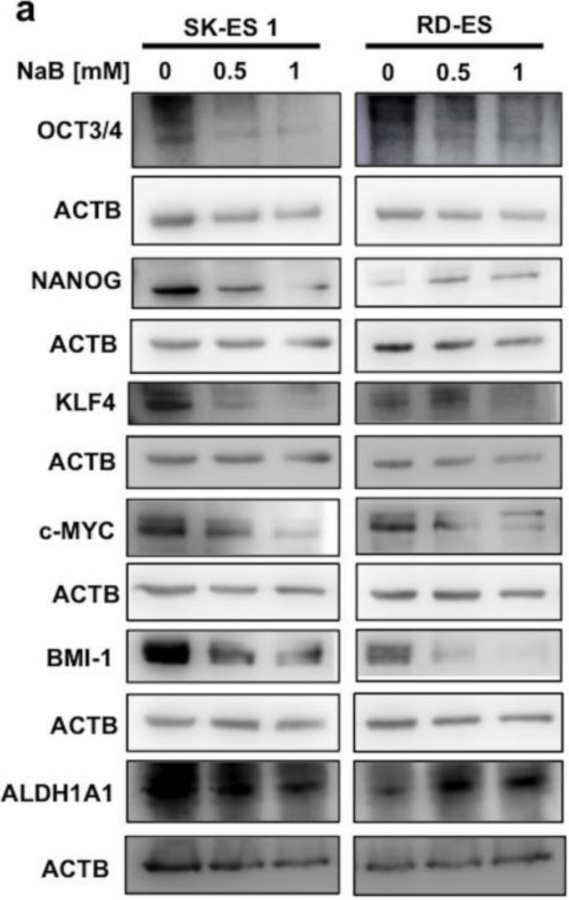

b
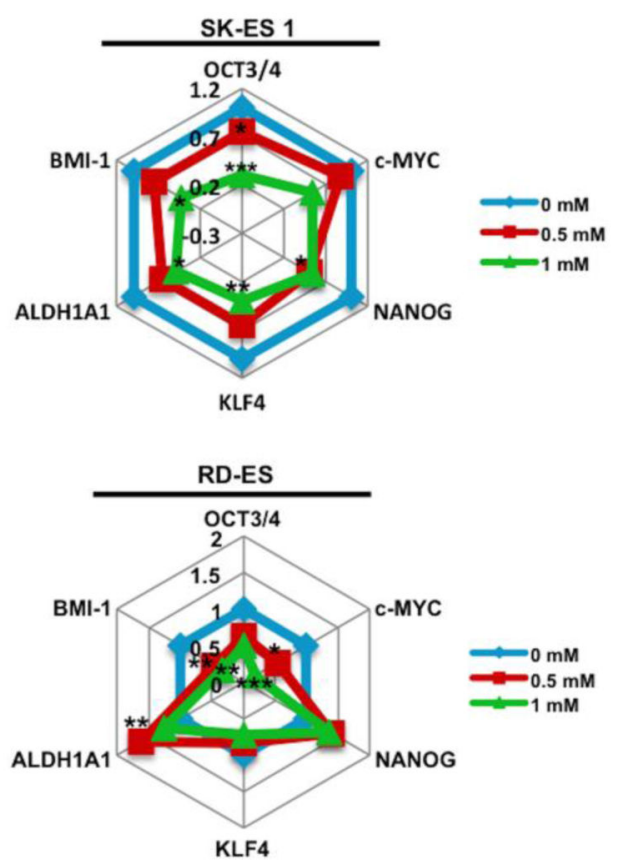

Figure 5. Changes in the expression of pluripotency-associated genes induced by HDAC inhibition in EWS cells.

(a) Western Blot analysis of pluripotency-associated genes in SK-ES 1 (left panel) and RDES (right panel) cells after $72 \mathrm{~h}$ of exposure to NaB. (b) Radar graph showing Relative Densitometric Unit (RDU) analyses normalized by ACTB level, and corrected by control; * $\mathrm{p}<0.05, * * \mathrm{p}<0.01, * * * \mathrm{p}<0.001$ vs. controls. 
a

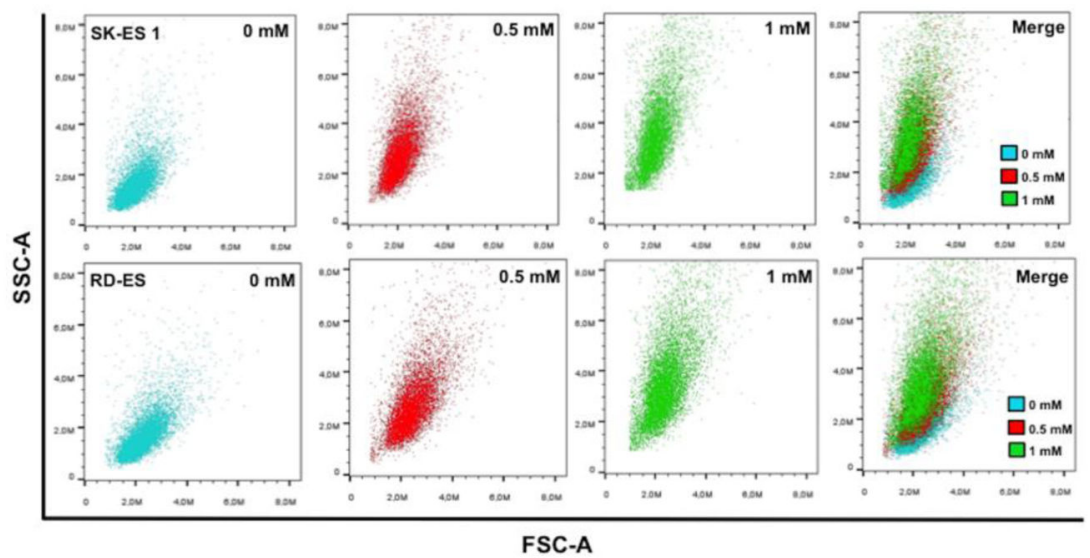

b
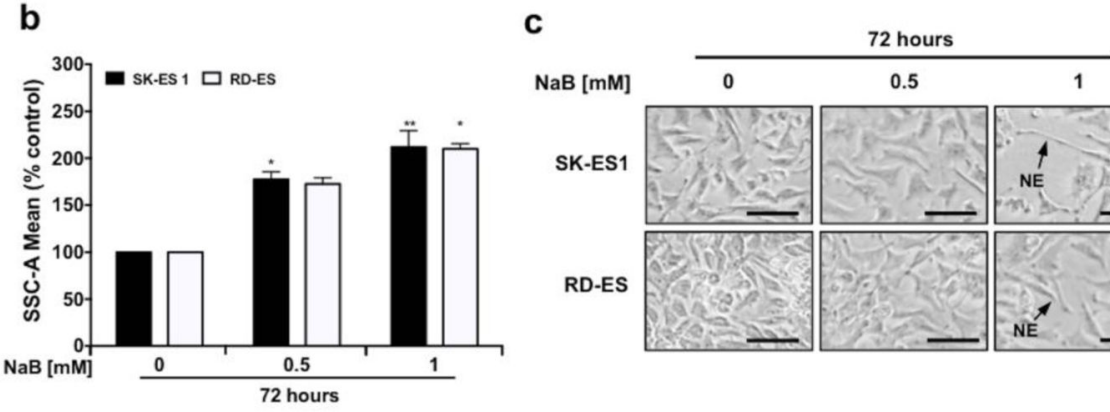

$\mathrm{NaB}[\mathrm{mM}]$

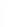

d

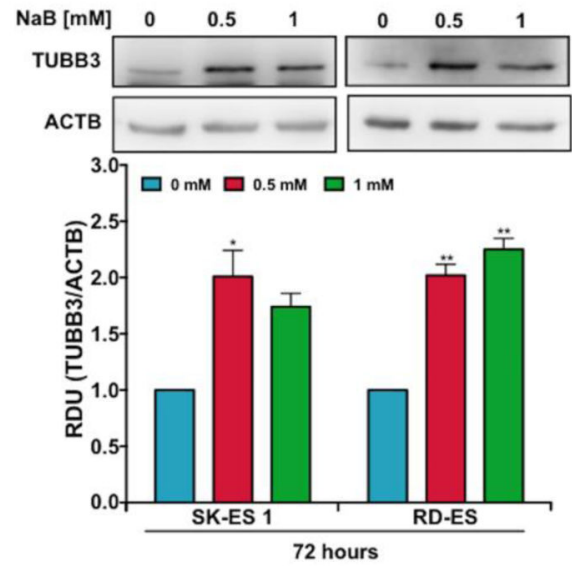

Figure 6. Cell complexity and differentiation of EWS cells after HDAC inhibition.

(a) Representative scatter plot from SK-ES 1 (upper) and RD-ES (lower) exposed to NaB for $72 \mathrm{~h}$, measured by cytometric analysis. (b) Percent of SSC-A mean from EWS cells exposed with the indicated concentrations of $\mathrm{NaB}$ for $72 \mathrm{~h} ; n=4$ independent experiments. (c) Morphology of SK-ES 1 (upper panel) and RD-ES cells (lower panel) after $72 \mathrm{~h}$ of NaB exposure; black arrows indicate neurite-like extensions (NE). Scale bar: 50 $\mu \mathrm{m}$. (d) Western Blot analysis of the differentiation neural marker TUBB3 (upper panel); $n=3$ independent experiments, and Relative Densitometric Unit (RDU) analyses (lower panel) normalized by 
ACTB, and corrected by control. Data in the graph are shown as mean \pm S.E.M; $* \mathrm{p}<0.05$, $* * \mathrm{p}<0.01$ vs. controls. 
a
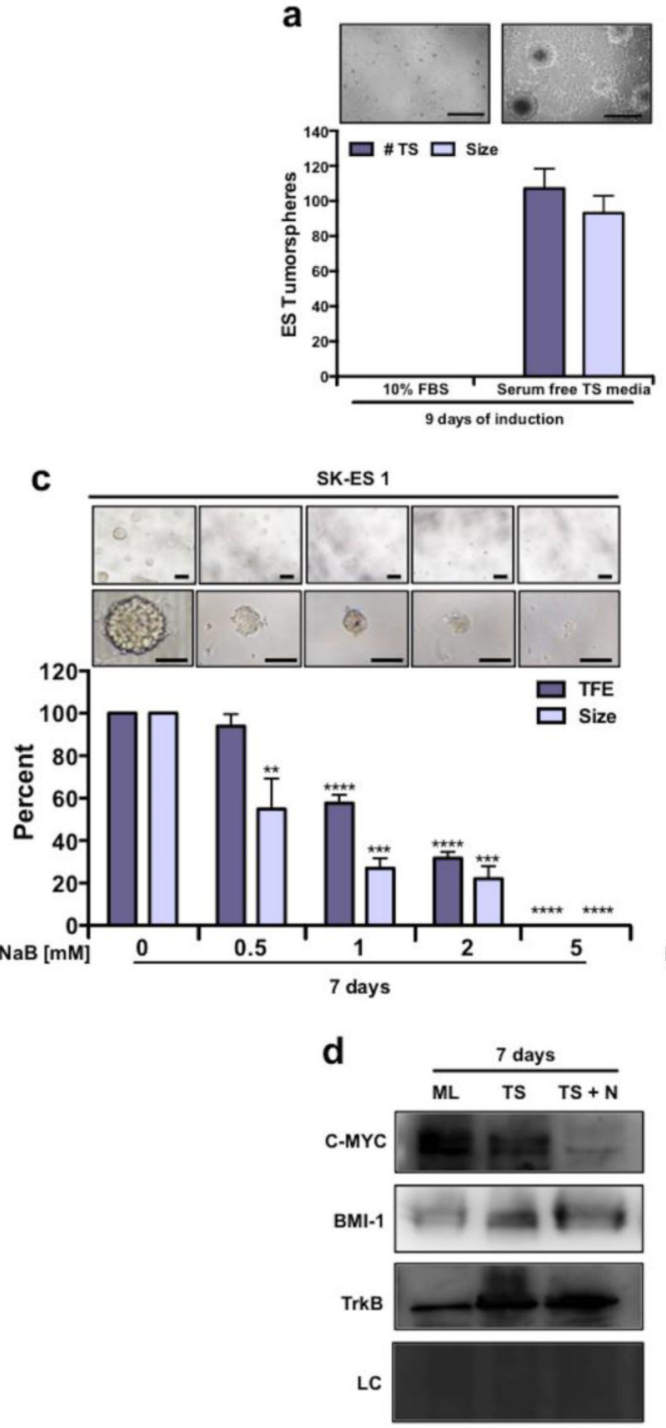
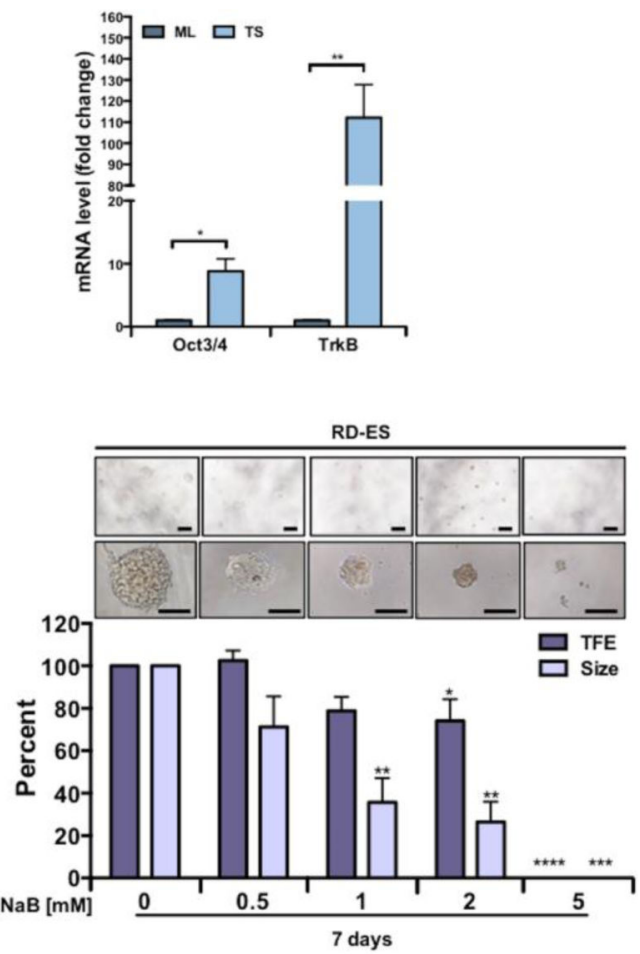

e

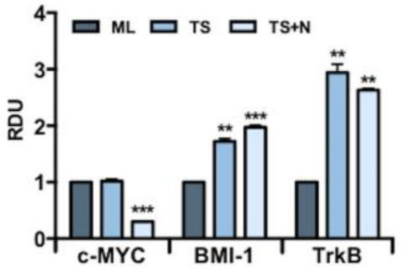

Figure 7. Reduced tumorsphere formation in EWS cells after HDAC inhibition.

(a) Percent of number and size of EWS tumorspheres from SK-ES 1 induced with a serumfree tumorspheres medium compared with $10 \%$ FBS medium for 9 days; $n=3$ independent experiments. (b) Oct3/4 and TrkB mRNA levels in SK-ES 1 cells grown in monolayer (10\% FBS medium) and tumorspheres (serum-free tumorspheres medium) induced for 9 days. Gene expression levels were normalized by gapdh level and corrected by monolayer; $n=3$ independent experiments. (c) Representative images from EWS tumorspheres from SK-ES1 (upper left panel) and RD-ES (upper right panel) cells after 7 days of $\mathrm{NaB}$ exposure. The percentage of EWS tumorspheres formation efficiency (TFE) (number of tumorspheres normalized by the number of plated single cells and corrected by control (lower panel) and the size of EWS tumorspheres is shown. Only tumorspheres $\geq 80$ um were analyzed. Scale bars: $200 \mu \mathrm{m}$ (upper), $100 \mu \mathrm{m}$ (lower); $n=3$ independent experiments. (d) Western blot of cMYC, BMI-1 and TrkB in SK-ES 1 cells in monolayer (ML), Tumospheres (TS) induced for 7 days, and tumospheres exposed to $1 \mathrm{mM}$ of $\mathrm{NaB}$ for 7 days $(\mathrm{TS}+\mathrm{N}) ; n=3$ independent 
experiments. (e) Relative Densitometric Unit (RDU) analyses were normalized by coomassie loading control, and corrected by monolayer. Data in the graphs are shown as mean \pm s.e.m.; $* \mathrm{p}<0.05, * * \mathrm{p}<0.01, * * * \mathrm{p}<0.001$, and $* * * * \mathrm{p}<0.0001$ vs. controls. 


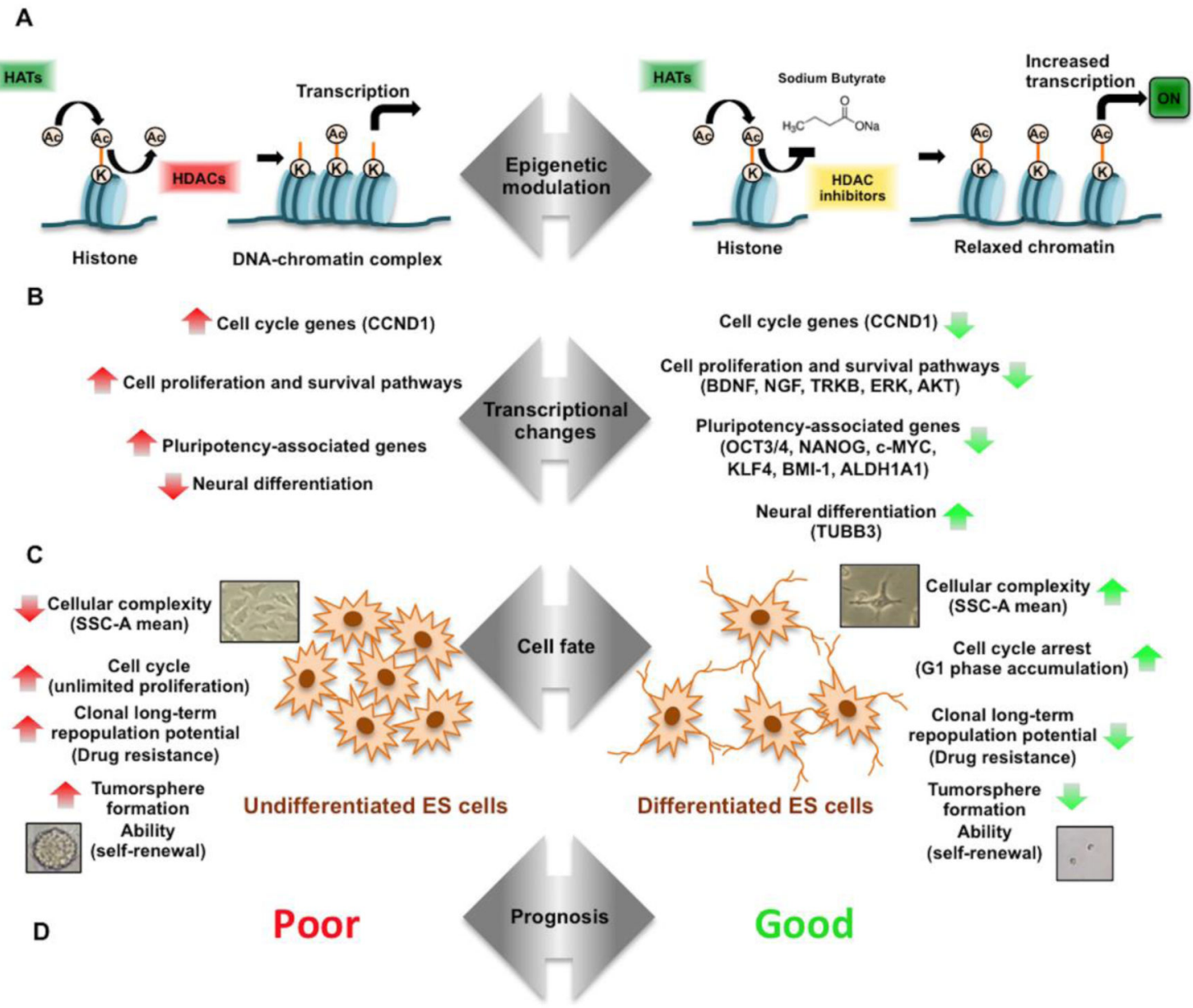

Figure 8. Schematic model depicting biological actions HDAC inhibition by NaB in EWS. (a) Unbalance between the activities of histone acetyltransferases (HATs) and histone deacetylases (HDACs) results in an aberrant epigenetic state that occurs often in EWS cells. HDAC inhibitors such as $\mathrm{NaB}$ have been employed to revert this setting by increasing histone acetylation and gene transcription. (b) As a result of epigenetic dysregulation, EWS cells present an aberrant expression of genes associated cell cycle, proliferation, survival, and pluripotency pathways. HDAC inhibition by $\mathrm{NaB}$ leads to transcriptional change by suppressing cell cycle, proliferation, survival, and pluripotency-associated genes, whereas de-repressing expression of the neural differentiation protein TUBB3. (c) A poor differentiated phenotype is a feature of EWS. HDAC inhibition change cell fate towards increased cellular complexity, arrested cell growth by G1-phase accumulation, decreased long-term clonal repopulation and reduced tumorsphere formation. Inhibiting HDAC might epigenetically reprogram EWS cells from an undifferentiated to a more differentiated state associated with a better prognosis $(\mathbf{d})$. 